\title{
Performance of Sorbent Particles for Removal of Cadmium in Hot Gas*
}

\author{
Ryo YOSHIIE**, Shinya GOTO***, \\ Makoto NISHIMURA** and Hiroshi MORITOMI***
}

\begin{abstract}
The use of particulate kaolinite as a sorbent for capturing cadmium compounds in hot flue gas was studied in the influence of temperature and residence time on removal efficiency. More than a half of the cadmium fed into the reactor was captured by kaolinite samples. It was also found that the amount of cadmium captured increased with time and that the removal efficiency at a temperature of $1073 \mathrm{~K}$ was slightly higher than at $873 \mathrm{~K}$. To clarify the mechanism of cadmium adsorption, the solubility of cadmium captured by particulate kaolinite was examined in both water and nitric acid. Acid-soluble cadmium constituted more than $80 \%$ of the total captured cadmium, while water-soluble cadmium constituted between $40-80 \%$. This suggests that cadmium does not penetrate into the kaolinite particles, but it remains on the surface and that physical condensation accounts for approximately half of the cadmium aerosol captured by kaolinite particles.
\end{abstract}

Key Words: Environmental Engineering, Pollutant, Solid Fuel, Hot Flue Gas, Sorbent Particles, Cadmium Removal

\section{Introduction}

Hazardous volatile heavy metals can be found in the flue gas following the combustion of coal and the incineration of waste products. It is widely known that they have a negative impact on the environment and human health if emitted into the atmosphere. As a consequence, the regulation of volatile metal emissions, such as $\mathrm{As}, \mathrm{Be}, \mathrm{Cd}, \mathrm{Co}, \mathrm{Cr}, \mathrm{Hg}, \mathrm{Ni}, \mathrm{Mn}, \mathrm{Pb}, \mathrm{Sb}$ and $\mathrm{Se}$, becomes stricter every year ${ }^{(1)}$. As volatile and semi-volatile metals tend to condense on fine particulate matter (PM) entrained in the flue gas, it is difficult to remove them by conventional dry flue gas treatment methods such as by using cyclone, bag filter or electrostatic precipitator techniques ${ }^{(2)}$. On the other hand, a wet flue gas treatment method like FGD has a higher performance to remove finer particulates

* Received 1st March, 2002

** Department of Human and Information Systems, Gifu University, 1-1 Yanagido, Gifu 501-1193, Japan. E-mail : ryoshiie@cc.gifu-u.ac.jp

*** Energy and Renewable Environmental Systems, Graduate School of Gifu University, 1-1 Yanagido, Gifu 501-1193, Japan because of its water scrubbing process and low working temperature. However, a hot gas cleaning process is a key factor to achieve higher thermal efficiencies in advanced power generation systems, such as IGCC. Reducing temperature of syngas to be clean in wet flue gas results in a drop of a thermal efficiency of a power generation plant. In addition, in the field of waste incineration, operating temperature in the furnace is going to be higher as a result of introducing ashmelting process. Then the objective of this study was to develop a dry flue gas treatment system for the removal of toxic heavy metals from flue gases at temperatures exceeding $800 \mathrm{~K}$.

The utilization of several mineral compounds as sorbents to capture heavy metals in high temperature flue gases was proposed by some researchers. Such sorbents can be added into the flue gas using a packed bed or direct injection system. In either case, there is a need to estimate the fundamental abilities of sorbent particles to capture heavy metals. Mineral compounds, such as silica, alumina, kaolinite, bauxite, limestone and bentonite, have been tested as possible sorbents. As a result, it has been confirmed that particulate kaolinite was effective at reactively 
scavenging lead and cadmium ${ }^{(3),(4)}$. Cadmium, which is a typical volatile heavy metal, is present in municipal and industrial waste, because cadmium compounds are widely used in fields such as the fabrication of corrosion-resistant metals and semiconductors. As with all toxic volatile metals, the emission of cadmium compounds need to be carefully controlled during the combustion process.

In this paper, the use of particulate kaolinite as a sorbent for capturing cadmium compounds was investigated. Using an ultrasonic nebulizer as a stationary feeding system for a cadmium aerosol, the transitional characteristics of cadmium adsorption under various experimental conditions was studied from the point of view of the influence of temperature and residence time on removal efficiency.

\section{Experimental Apparatus and Procedure}

The schematic of the experimental apparatus is shown in Fig. 1. The reactor was made of a $25 \mathrm{~mm}$ ID quartz tube with a length of $750 \mathrm{~mm}$. A packed bed sorbent formed from $1 \mathrm{~g}$ of particulate kaolinite supported by silica paper and a ceramic frame was placed at the center of the reactor tube. Three different particle sizes $(<10 \mu \mathrm{m}, 75 \sim 125 \mu \mathrm{m}, 250 \sim 500$ $\mu \mathrm{m}$ ) of particulate kaolinite samples (sample A, B and $C$ respectively) were tested as sorbent particles. The temperature in the reactor was controlled by an electric furnace with a programmable controller (KP $1200 \mathrm{CHINO}$ ). The kaolinite particles in the reactor were pre-heated for 10 minutes to transform them into meta-kaolinite in advance of starting the test.

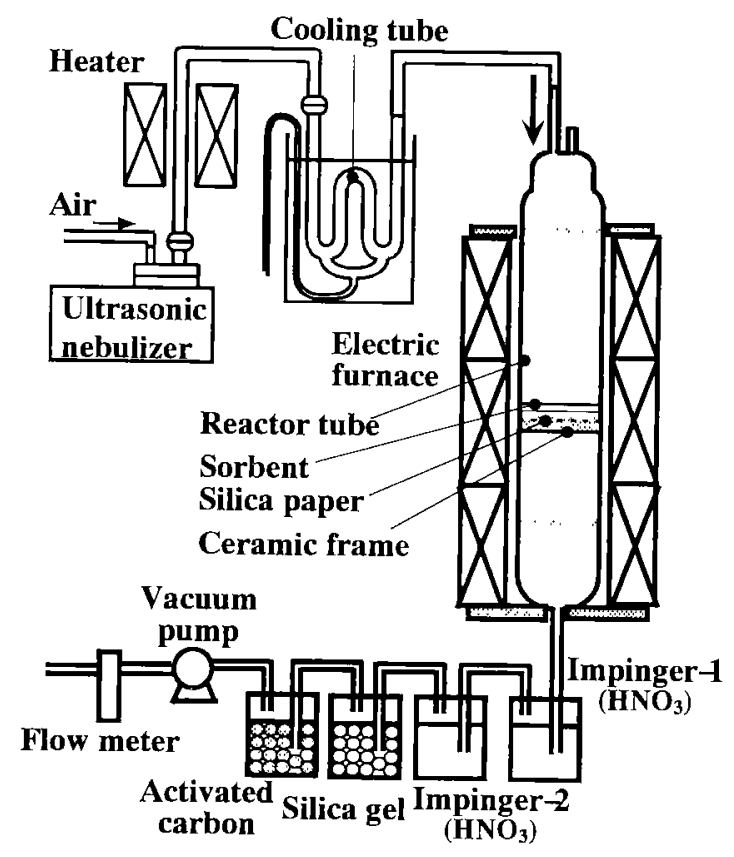

Fig. 1 Schematic of experimental apparatus for cadmium adsorption
An ultrasonic nebulizer system (NE-U12 OMRON) was used to feed the cadmium nitrate solution into the reactor in the form of an aerosol entrained by air. This system utilized a water condensation process to reduce moisture in the sample gas flowing into the reactor. The air flow rate in the reactor, which was controlled using a vacuum pump at the downstream of the reactor, was $2 \mathrm{~L} / \mathrm{min}$. Cadmium concentration in the gas, which is dependent on the concentration of cadmium in the solution fed by the nebulizer, was calibrated before every test. During the test for cadmium removal, particulate kaolinite samples in the reactor were exposed to a gas including the cadmium aerosol for 20,40 or 60 minutes at a given temperature.

To measure the content of cadmium captured by the sorbent after the exposure, sample particles were dissolved in a $\mathrm{HNO}_{3} / \mathrm{HCl} / \mathrm{HF}(3 / 9 / 4$ volumetric ratio) mixture. In addition, water-soluble cadmium and acid-soluble cadmium contents were estimated separately from the total captured cadmium to facilitate an investigation of the chemical forms of the captured cadmium. Both of these measures were obtained by rinsing sample particles with water or $(1+15) \mathrm{HNO}_{3}$ respectively. In all cases, elemental cadmium in the solutions was quantified via an atomic absorption spectrometer (AA-6800 SHIMADZU). Experimental conditions are summarized in Table 1.

\section{Results and Discussion}

\subsection{Cadmium adsorption and removal efficiencies}

The effect of cadmium concentration in gas, particle size and reaction temperature on the capture of cadmium by particulate kaolinite is discussed in this section. Temporal profiles of the captured cadmium under various experimental conditions are given in Figs. 2 to 5 . Figure 2 illustrates the experimental results for a cadmium concentration of 4.63 $\mathrm{mg} / \mathrm{m}^{3}$, whilst three remaining figures illustrates the results for a cadmium concentration of $10.45 \mathrm{mg} / \mathrm{m}^{3}$. The effects of particle size on the same cadmium concentration can be observed in Figs. 3, 4 and 5. In all cases, the amount of captured cadmium increased linearly with time and the adsorption was not saturat-

Table 1 Experimental conditions

\begin{tabular}{|c|c|}
\hline Weight of sorbent $(\mathrm{g})$ & 1.0 \\
\hline Temperature $(\mathrm{K})$ & 873,1073 \\
\hline Cd concentration in gas $\left(\mathrm{mg} / \mathrm{m}^{3}\right)$ & $4.63,10.45$ \\
\hline Reaction time $(\mathrm{min})$ & $20,40,60$ \\
\hline & Sample A <10 \\
Particle size $(\mu \mathrm{m})$ & Sample B 75 125 \\
& Sample C 250 $\sim 500$ \\
\hline Gas flow rate $(\mathrm{L} / \mathrm{min})$ & 2.0 \\
\hline
\end{tabular}




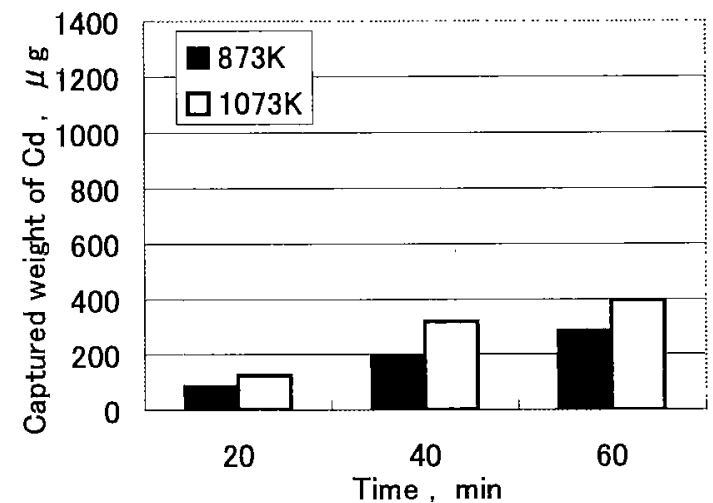

Fig. 2 Temporal profile of total captured Cd on sample A $(<10 \mu \mathrm{m})$. Cd concentration; $4.63 \mathrm{mg} / \mathrm{m}^{3}$

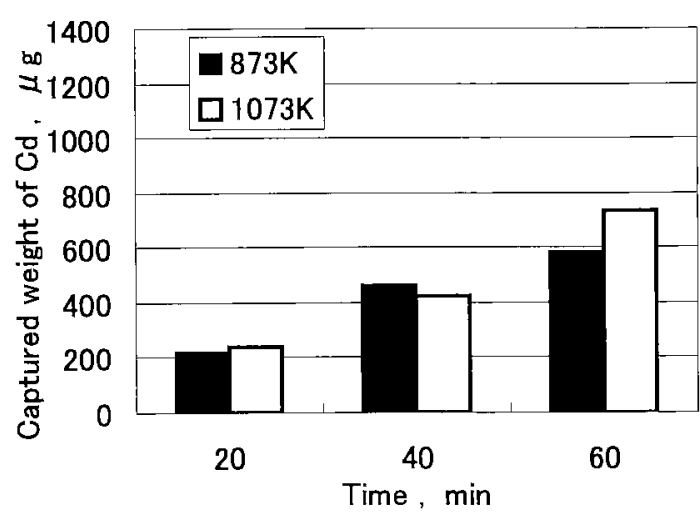

Fig. 3 Temporal profile of total captured Cd on sample A $(<10 \mu \mathrm{m})$. Cd concentration ; $10.45 \mathrm{mg} / \mathrm{m}^{3}$

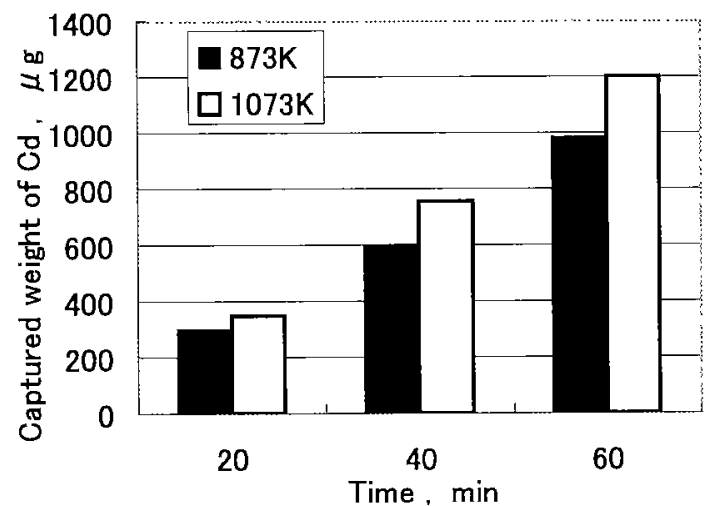

Fig. 4 Temporal profile of total captured Cd on sample B (75 125 $\mu \mathrm{m})$. Cd concentration; $10.45 \mathrm{mg} / \mathrm{m}^{3}$

ed after $60 \mathrm{~min}$. Cadmium removal efficiencies, defined as the ratio of total captured cadmium to cadmium injected into the reactor at a given time, are also estimated. These efficiencies are shown in Figs. 6 to 9 and correspond to Figs. 2 to 5 respectively. It was found that removal efficiency does not decay with time and is dependent on both temperature and particle size.

3.1.1 Effects of cadmium concentration From comparison of Figs. 2 and 3, it can be seen that higher

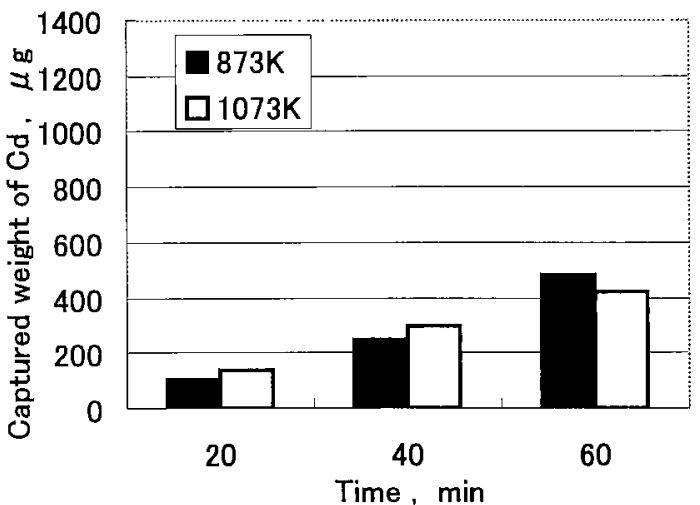

Fig. 5 Temporal profile of total captured Cd on sample C $(250 \sim 500 \mu \mathrm{m})$. Cd concentration ; $10.45 \mathrm{mg} / \mathrm{m}^{3}$

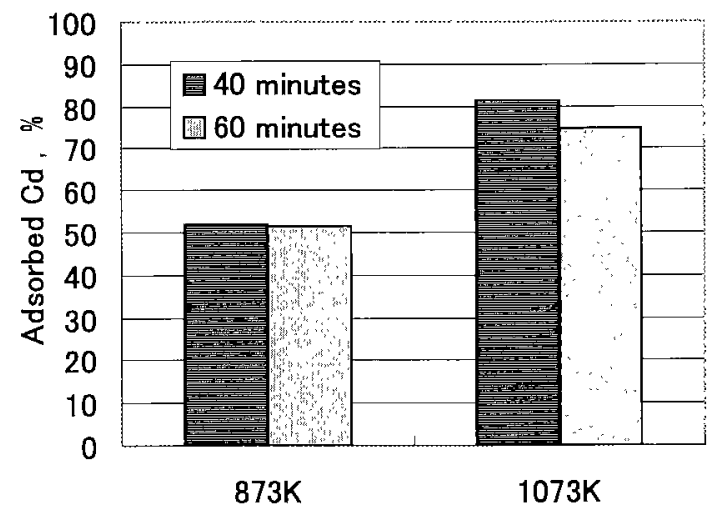

Fig. 6 Cadmium removal efficiencies, sample A $\quad<10$ $\mu \mathrm{m})$. Cd concentration; $4.63 \mathrm{mg} / \mathrm{m}^{3}$

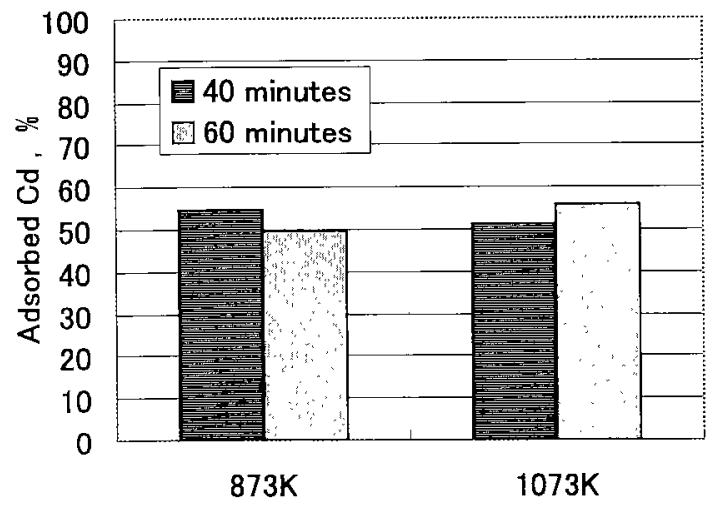

Fig. 7 Cadmium removal efficiencies, sample A $\quad<10$ $\mu \mathrm{m})$. Cd concentration; $10.45 \mathrm{mg} / \mathrm{m}^{3}$

cadmium concentration in the gas leads to a larger adsorption of cadmium at temperatures of $873 \mathrm{~K}$ and $1073 \mathrm{~K}$. With a cadmium concentration of $4.63 \mathrm{mg} /$ $\mathrm{m}^{3}$, removal efficiency at $1073 \mathrm{~K}$ was higher than at $873 \mathrm{~K}$, as shown in Fig. 6. On the other hand, when cadmium concentration in the gas was $10.45 \mathrm{mg} / \mathrm{m}^{3}$, removal efficiency was independent of reaction temperature as shown in Fig. 7. It is noted that removal efficiency at $1073 \mathrm{~K}$. decreased with an increase in cadmium concentration, whilst it was near constant at 


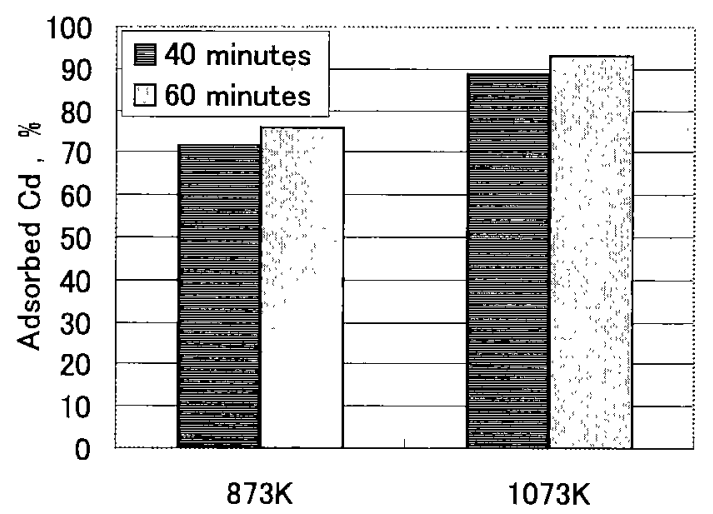

Fig. 8 Cadmium removal efficiencies, sample B (75 125 $\mu \mathrm{m})$. Cd concentration; $10.45 \mathrm{mg} / \mathrm{m}^{3}$

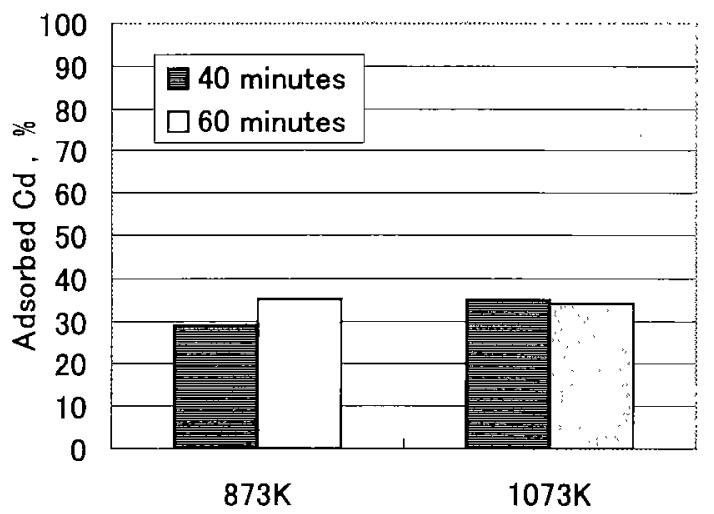

Fig. 9 Cadmium removal efficiencies, sample C (250 $~ 500$ $\mu \mathrm{m})$. Cd concentration; $10.45 \mathrm{mg} / \mathrm{m}^{3}$

$873 \mathrm{~K}$. This suggests that cadmium adsorption by particulate kaolinite under these experimental conditions cannot be regarded as a simple 1st-order reaction against the cadmium concentration in gas.

3.1.2 Effects of particle size The effect of particle size on cadmium adsorption can be investigated by comparison of Figs. 3, 4 and 5. The amount of cadmium captured by sample B was greater than that captured by samples $\mathrm{A}$ and $\mathrm{C}$ regardless of temperature and time. Figures 7, 8 and 9 also show that the most efficient removal was obtained using sample B. In general, reaction rates in fluid-particle systems depend on the specific surface area of the particles. This would suggest that small particles, which have a large specific surface area, exhibit high adsorption properties. However, in our experimental results, sample A exhibited a lower adsorption effect than sample $B$. This indicates that the effective specific surface area of sample A might be smaller than the real value. Small particles will adhere to each other to form larger particles, especially in a packed bed system. When this happens, the effective specific surface area of the particles decreases. It is expected that this behavior considerably occurred only in tests with using sample A.

3.1.3 Effects of reaction temperature The effect of reaction temperature on cadmium adsorption could not be clearly observed in this study. Adsorbed cadmium and removal efficiency by sample $\mathrm{A}$ for a cadmium concentration of $4.63 \mathrm{mg} / \mathrm{m}^{3}$ increased with an increase in temperature, as shown in Figs. 2 and 6. However, the results for a cadmium concentration of $10.45 \mathrm{mg} / \mathrm{m}^{3}$ did not change significantly, as shown in Figs. 3 and 7. Figure 4 suggests that sample B captured more cadmium at $1073 \mathrm{~K}$ than at $873 \mathrm{~K}$, but the amount of cadmium captured by sample $\mathrm{C}$ did not increase with an increase in temperature, as shown in Fig. 5. Furthermore, Figs. 8 and 9 suggest that the effect of particle size on cadmium adsorption is much significant than the effect of reaction temperature. Based on these results, we can state that reaction temperature does not significantly affect cadmium adsorption in the experimental conditions tested in this study. This indicates that chemical adsorption is less dominant than physical condensation on the particles in the present system. However, some researchers have confirmed, via $\mathrm{XRD}$ analysis, that $\mathrm{CdO}, \mathrm{Al}_{2} \mathrm{O}_{3}, 2 \mathrm{SiO}_{2}$ and $2 \mathrm{CdO}, \mathrm{Al}_{2} \mathrm{O}_{3}, 2 \mathrm{SiO}_{2}$ was formed as a result of cadmium adsorption by particulate kaolinite and concluded that chemical reaction was the dominant mechanism of cadmium capture by particulate kaolinite ${ }^{(5)-(7)}$. This discrepancy between previous reports and the present study might be caused by differences in the chemical form of the cadmium injected into the reactor. In previous experiments carried out by Uberoi ${ }^{(5)}$, cadmium was present in the reactor as cadmium chloride vapor. By comparison, in the present study, the cadmium existed as an aerosol of cadmium nitrate fed by an ultrasonic nebulizer and the temperature in the reactor was not high enough for the cadmium nitrate to vaporize completely. It is a simple process to capture cadmium compounds in solid and liquid phases via physical condensation. The identification of the chemical forms of cadmium compounds in the combustion process is important for the design of systems for cadmium adsorption by sorbent particles.

\section{2 Chemical form of captured cadmium}

The solubility of the captured cadmium in water and acid was examined to quantify the chemical form of the captured cadmium. The water-soluble or acidsoluble cadmium fractions of the total cadmium captured by particulate kaolinite at $873 \mathrm{~K}$ are shown in Fig. 10 (a), (b) and (c), and the fractions at $1073 \mathrm{~K}$ are shown in Fig. 11 ( a ), (b) and (c). The three particulate kaolinite samples were tested at each temperature. The cadmium concentration in the gas was $10.45 \mathrm{mg} / \mathrm{m}^{3}$ for all tests referred to in this 

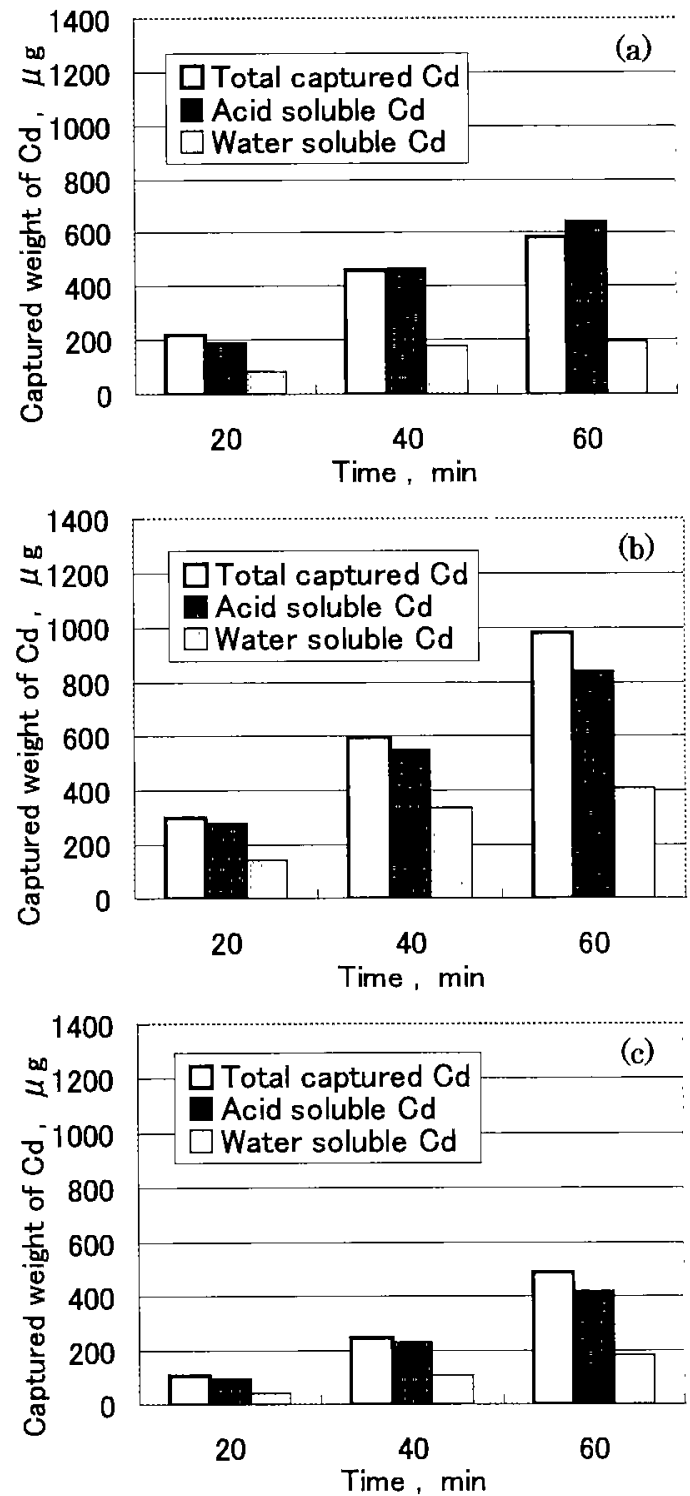

Fig. 10 Chemical forms of captured cadmium on (a) sample A $(<10 \cdot \mu \mathrm{m})$, (b) sample B $(75 \sim 125 \mu \mathrm{m})$ and $(\mathrm{c})$ sample $C(250 \sim 500 \mu \mathrm{m})$ at temperature of $873 \mathrm{~K}$. Cd concentration; $10.45 \mathrm{mg} / \mathrm{m}^{3}$

section. As shown in these figures, more than $80 \%$ of the fraction was acid-soluble cadmium, independent of temperature or particle size. A large amount of acid-soluble cadmium indicates that cadmium captured by particulate kaolinite exists on the surface of kaolinite particles. If cadmium compounds penetrate the kaolinite particles, they are effectively non-soluble in acid because dilute acid, such as the $(1+15)$ $\mathrm{HNO}_{3}$ used in the present study, will hardly dissolve particulate kaolinite. The fraction of water-soluble cadmium was distributed over a range from $40 \%$ to $80 \%$. It was observed to decrease at a temperature of $1073 \mathrm{~K}$ with between readings at $40 \mathrm{~min}$ and $60 \mathrm{~min}$. Water-soluble cadmium can be considered physically condensed cadmium on the kaolinite particles, and
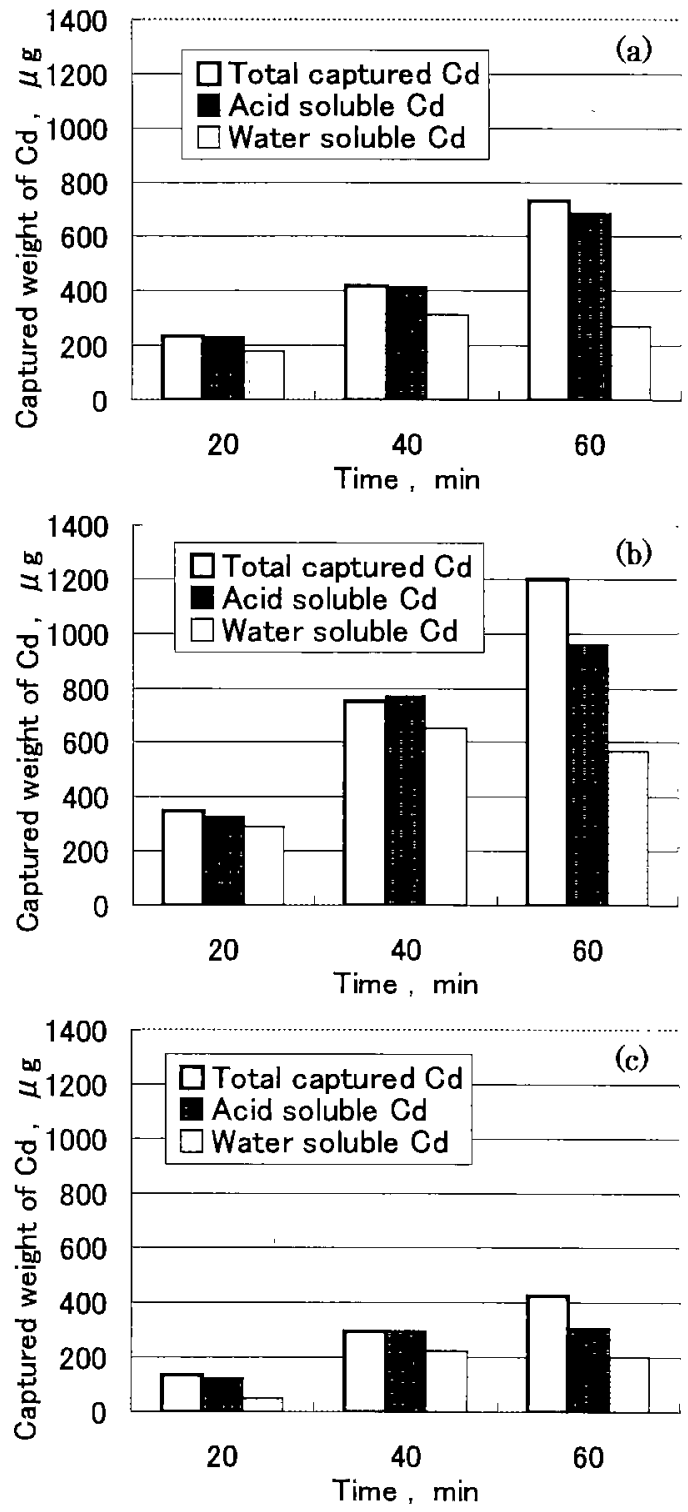

Fig. 11 Chemical forms of captured cadmium on (a) sample A $(<10 \mu \mathrm{m})$, (b ) sample B $(75 \sim 125 \mu \mathrm{m})$ and (c) sample $C(250 \sim 500 \mu \mathrm{m})$ at temperature of $1073 \mathrm{~K}$. Cd concentration; $10.45 \mathrm{mg} / \mathrm{m}^{3}$

acid-soluble cadmium includes chemically adsorbed cadmium. Then, the difference between water-soluble and acid-soluble cadmium results from chemical adsorption. From Figs. 10 and 11, physical condensation is found to be comparable to or more dominant than the chemical reaction for cadmium adsorption in the present study.

However, oxidization of the captured cadmium also increases this difference. As cadmium aerosol is entrained by air containing oxygen in the system, cadmium nitrate can convert to cadmium oxide after it is physically condensed on the particulate kaolinite. Cadmium oxide is acid-soluble but not water-soluble and exists as a solid phase even at temperatures in excess of $1073 \mathrm{~K}$. The decrease in the fraction of 
water-soluble cadmium between $40 \mathrm{~min}$ and $60 \mathrm{~min}$ at $1073 \mathrm{~K}$ might result from development of oxidization of the captured cadmium. It can be concluded that physical condensation accounts for approximately half of the captured cadmium aerosol by particulate kaolinite.

\section{Conclusions}

A study of cadmium captured by particulate kaolinite at temperatures between $873 \mathrm{~K}$ and $1073 \mathrm{~K}$ was completed by feeding aerosol of cadmium nitrate into a reactor. The study resulted in the following conclusions ;

(1) The amount of captured cadmium increase linearly with time and removal efficiency did not decay over $60 \mathrm{~min}$.

(2) Particle size of the kaolinite sorbent affects cadmium adsorption. The maximum removal efficiency was obtained with samples with a particle size between $75 \mu \mathrm{m}$ and $125 \mu \mathrm{m}$.

(3) Removal efficiency at $1073 \mathrm{~K}$ was slightly higher than at $873 \mathrm{~K}$. However, reaction temperature had little effect on the amount of cadmium adsorption.

(4) Between $40-80 \%$ of the total captured cadmium was water-soluble, and more than $80 \%$ was acid-soluble. This suggests that cadmium captured by particulate kaolinite principally remains on the surface of the kaolinite particles.

(5) Physical condensation accounts for approximately half of the captured cadmium aerosol by kaolinite particles.

\section{References}

(1) Biswas, P. and Wu, C.Y., Control of Toxic Metal Emissions from Combustors Using Sorbent: A Review, J. Air \& Waste Manage. Assoc., Vol. 48 (1998), pp. 113-127.

(2) Wendt, J. and Linak, W.P., Toxic Metal Emissions from Incineration: Mechanisms and Control, Prog. Energy Combust. Sci., Vol. 19 (1993), pp. 145-185.

(3) Sonoda, K., Yoshida, S., Tsuboi, T., Moritomi, H., Yoshiie, R. and Tsuji, T., Behavior on Heavy Metal Emissions in Fluidized Bed Incineration Process and High Temperature Removal Technology by Sorbent, Proc. of The 5th SCEJ Symposium on Fluidization, (in Japanese), (1999), pp. 302-308.

(4) Moritomi, H. and Yoshiie, R., Emission Behavior, Control and Monitoring Systems of Trace Elements from Combustion Processes, Proc. of The 7th National Symposium on Power and Energy System, (2000), pp. 113-116.

(5) Uberoi, M. and Shadam, F., High-Temperature Removal of Cadmium Compounds Using Solid Sorbents, Environ. Sci. Technol., VoI. 25, No.7 (1991), pp. 1285-1289.

(6) Masseron, R., Gadiou, R. and Delfosse, L., Study of the Adsorption of $\mathrm{CdCl}_{2}$ Vapor on Various Minerals Using a Drop Tube Furnace, Environ. Sci. Technol., Vol. 33, No.20 (1999), pp. 36343640.

( 7 ) Yang, H.C., Yun, J.S., Kang, M.J., Kim, J.H. and Kang, Y., Capture of Volatile Hazardous Metals Using a Bed of Kaolinite, Korean J. Chem. Eng., Vol. 16, No. 5 (1999), pp. 646-653. 